\title{
Fostering diversity work as a process of lifelong learning: A partnership case study with an immigrant services organisation
}

\author{
Hongxia Shan ${ }^{1}$ (D) $\cdot$ Amy Cheng $^{2} \cdot$ Nasim Peikazadi $^{1} \cdot$ Yeonjoo Kim $^{1}$
}

Accepted: 11 November 2021 / Published online: 22 November 2021

(c) UNESCO Institute for Lifelong Learning and Springer Nature B.V. 2021

\begin{abstract}
Diversity work is an area of growing interest for organisations in both the private and public sectors. In a nutshell, the term refers to the work conducted within an organisation that promotes inclusive and equitable engagement with people and communities across social differences such as gender, race, ethnicity, sexuality and religion. Related research has generated relatively more knowledge about the challenges and problems of diversity initiatives than about effective practices that genuinely foster social equity and inclusion. This article contributes to the latter with a partnership case study involving the United Chinese Community Enrichment Services Society (S.U.C.C.E.S.S.), a large non-profit immigrant services organisation headquartered in Vancouver, Canada. Specifically, the study presented here focuses on the organisational practices that are constitutive of frontline workers' engagement with diversity work and learning. It shows that (1) building a diverse and inclusive organisation, (2) supporting continuous learning opportunities at work, and (3) providing diversity training, both directive and generative, form the organisation's diversity "curriculum". This study also demonstrates that the strength of this workplace curriculum is that it has the potential to challenge the boundary between instrumentalism (harnessing diversity work to business success) and equity activism (prioritising diversity work in its own right), and that it creates space for collective reflection in the presence of others. Conceptually drawing on the practice turn in social sciences, particularly Steven Billet and Jennifer Newton's learning practice, and what David Boud terms "the reflective turn", this article positions diversity work as a reflective and iterative process of lifelong learning for both organisations and individual workers.
\end{abstract}

Keywords Diversity work · Lifelong learning · Work and learning · Diversity training $\cdot$ Partnership case study

Hongxia Shan

hongxia.shan@ubc.ca

Extended author information available on the last page of the article 


\section{Résumé}

Encourager le travail de diversité en tant que processus d'apprentissage tout au long de la vie : étude de cas en partenariat avec une organisation de services aux immigrants - Le travail de diversité (diversity work en anglais) est un domaine qui suscite un intérêt croissant tant dans le secteur privé que dans le secteur public. Pour faire court, cette expression renvoie au travail mené au sein d'une organisation qui promeut un engagement inclusif et équitable auprès de personnes et de communautés en dépassant les différences sociales comme le genre, la race, l'ethnicité, la sexualité et la religion. Les recherches liées à cela ont produit relativement plus de connaissances concernant les défis et problèmes des projets sur la diversité que sur les pratiques efficaces qui favorisent réellement l'équité sociale et l'inclusion. Cet article contribue à ces dernières en présentant une étude de cas en partenariat avec la United Chinese Community Enrichment Services Society (S.U.C.C.E.S.S.), grande organisation à but non lucratif de services aux immigrants, dont le siège se situe au Canada, à Vancouver. L'étude présentée ici est axée en particulier sur les pratiques organisationnelles constitutives de l'engagement des travailleurs sur le terrain en matière du travail de diversité et d'apprentissage. Elle montre que (1) créer une organisation diverse et inclusive, (2) soutenir des possibilités d'apprentissage continu au travail et (3) proposer une formation à la diversité, tant directive que générative, façonne le « curriculum » de l'organisation en matière de diversité. Cette étude démontre également que la puissance de ce curriculum sur le lieu de travail réside dans ses possibilités de repousser les limites entre l'instrumentalisme (qui exploite le travail de diversité pour la réussite de l'entreprise) et l'activisme en matière d'équité (qui priorise le travail de diversité à part entière). S'appuyant sur le plan conceptuel sur le tournant pratique dans les sciences sociales (practice turn en anglais), notamment sur la pratique de l'apprentissage de Steven Billet et Jennifer Newton, et sur ce que David Boud appelle «le tournant réflexif » (the reflexive turn), cet article positionne le travail de diversité en tant que processus réflexif et itératif d'apprentissage tout au long de la vie, tant pour les organisations que pour les travailleurs individuels.

\section{摘要}

促进多元化工作的终生学习: 一个基于和移民服务组织机构的合作案例分析 多元化工作是营利和非营利组织机构越来越感兴趣的领域。简而言之, 该术语 指的是在组织机构中开展跨越性别、种族、民族、性取向和宗教等社会差异, 以提升工作的包容性和公平参与性。相关文献更多的硏究了促进多元化工作 的众多措施面临的挑战和问题, 而对真正促进社会公平和包容的有效实践的研 究涉猎较少。基于和中侨互助会 (S.U.C.C.E.S.S.) - 一个总部设立在加拿大温 哥华的非营利性组织一合作开展的案例分析, 本硎究对后者文献上进行补足。 具体来说, 本文侧重于研究促进一线员工参与多元化工作和学习的组织行为。 调硏结果显示以下组织行为形成了建构多元化工作的“课程”: (1) 建立一个多 元化和包容性的机构, (2) 支持工作中的持续学习机会, 以及 (3) 提供指导性和 生成性的多元化培训。这项㸴究还表明, 这些组织行为的优势在于他们有可能 挑战功利主义 (利用多元化工作取得商业效果) 和平等行动主义 (多元化工作促 进多元利䀂) 之间的界限，并且提供了有他人在场的集体反思的空间。该㸴究 从理论概念上借鉴了社会科学中的实践理论转向, 特别是史蒂文.比勒 (Steven 
Billet) 和詹妮弗.牛顿 (Jennifer Newton) 的学习实践理论, 以及大卫.布德 (David Boud) 所倡导的“反思转向”, 将多元化工作定位为组织机构和个体员工具有反 思性的, 迭代性的终身学习过程。

\section{Introduction}

In countries such as the United States (US) and Canada, organisations are increasingly compelled to take up issues of diversity and inclusion as a result of legal stipulation, policy requirements, the shifting demographic of the workforce, and a neoliberal economic reasoning that sees diversity as a business advantage (Klarsfeld et al. 2012; Kwon and Nicolaides 2017). Indeed, the increase in the usage of the term seems to have prompted the editors of the Oxford English Dictionary to extend the dictionary's online definitions of diversity by two "draft additions" as recently as September 2021:

the fact, condition, or practice of including or involving people from a range of different social and ethnic backgrounds, and (more recently) of different genders, sexual orientations, etc. (OED online 2021),

and

as a modifier, with the sense "of or relating to ethnic, social, gender, etc., diversity" ... "that encourages or ensures diversity", as in diversity officer, diversity quota, diversity training, etc. (ibid.; italics in original).

By extension, the composite term diversity work has also emerged and is used with increased frequency. However, as Amy Kahn remarks: "With authors and business leaders using so many different descriptions and metaphors to describe diversity work, it is important to define the meaning of diversity work and interventions" (Kahn 2013, p. 175). In our article, we use the term to refer to work conducted through an organisation that promotes inclusive and equitable engagements with others across social differences such as gender, race, ethnicity, sexuality and religion.

Today, diversity work is considered key to "the new equity regimes", i.e., the legal and managerial framing that positions equity as a "positive duty" for organisations (Ahmed and Swan 2006, p. 97). For organisations in both the private and public sectors, diversity has become an issue of interest if not priority. A range of diversity initiatives have been reported in the literature, including, but not limited to, gender mainstreaming, diversity hiring, diversity management and diversity training. Few of the diversity initiatives however are found to be effective in combating discrimination or creating inclusive organisations (Ballard et al. 2020; Hiranandani 2012). Reported issues include, but are not limited to, the co-optation of the equity agenda by the business agenda (Ely and Meyerson 2000; Mirchandani and Butler 2006), and an essentialised approach to identity (D'Cruz 2007; Zanoni et al. 2010) which denies the social constructedness of race, class and gender etc.. 
It is important to note that the literature on diversity work has generated relatively more knowledge about the challenges and problems associated with it than about practices that may help foster social equity and inclusion (Nkomo et al. 2019). This article contributes to the latter with an examination of organisational practices that are conducive to the diversity work and learning of frontline workers in immigrant services in Canada. Empirically, we draw on a partnership case study with the United Chinese Community Enrichment Services Society (S.U.C.C.E.S.S.), a large non-profit immigrant services organisation headquartered in Vancouver, a gateway city for immigration in Western Canada. Conceptually, our article builds on what Theodore Schatzki (2001) calls the practice turn in social sciences, ${ }^{1}$ and proposes diversity work as a process of lifelong learning for both individuals and organisations. We begin with a review of the literature on diversity work, before conceptualising diversity work as a process of lifelong learning. We then provide the context of our study and introduce S.U.C.C.E.S.S., the partnership organisation, followed by our research methodology and methods. The main body of our article is devoted to a discussion of our research findings before we conclude with a recap of the findings and a discussion of their theoretical and practical implications.

\section{Diversity work within organisations: development and problems}

Diversity work within an organisation is typically framed within two seemingly polarised positions: as an issue of social equity and justice (equity activism) versus the instrumentalist approach of regarding it as an issue of human resource management (HRM) (Kwon and Nicolaides 2017). Chang-kyu Kwon and Aliki Nicolaides's three paradigms of diversity work (ibid.), albeit with a focus on the US context, provide an overview of the environmental context and the varying orientations of diversity work. They name the first paradigm discrimination and fairness. Since the 1960s, various social movements have sought cultural recognition of marginalised identities, such as women and racialised groups, as well as equitable "redistribution" of economic opportunities and resources (Fraser 1997). Equity activism has led to the formulation of public policies, including equal opportunity and anti-harassment legislations that address issues of social difference and disparity within a human rights agenda. Given this changing legal context, to ward off costly diversity complaints or lawsuits, organisations have started taking up diversity issues by offering compliance training, for instance (O'Leary and Sandberg 2017).

Kwon and Nicolaides' second paradigm is access and legitimacy (Kwon and Nicolaides 2017), which arose in anticipation of a changing composition of the workforce towards the end of the 1980s. Within this paradigm, organisations provide training for underrepresented groups so that they might assimilate to the existing

\footnotetext{
1 The term practice turn is used by Schatzki (2001) to refer to the development of a range of practice theories that focus on (form the nexus of) practices for social analysis. While the constructs of practice vary, they all intend to bring together traditional dichotomies in social sciences such as the individual and the structural, the subject(ive) and the object(ive), and the human and non-human.
} 
systems of work. The third paradigm is learning and effectiveness (ibid.), which arose in the late 1990s, when the corporate world started recognising the business value of difference. To leverage the potentials of a diverse workforce, organisations began treating diversity work as a strategy instrumental to the success of a business (ibid.).

As diversity became mainstreamed as an organisational issue, it also incurred substantial criticism. One of the major critiques is plainly why diversity initiatives remain ineffective in combating social inequity and creating genuinely inclusive organisations (Nkomo et al. 2019). One explanation is that despite improvements of the legal and discursive environment, it is challenging to reach people at the level of practical consciousness (Giddens 1979), i.e., the habitual, routinised and unarticulated consciousness that might be implicated in the perpetuation of behaviour fostering social inequality and injustice (D'Cruz 2007; Young 2011). Another explanation is the possible displacement or co-optation of the activist agenda (Zanoni et al. 2010). In this regard, however, Elaine Swan and Steve Fox (2010) argue that managerial co-optation and equity interest in diversity issues do not have to be distinct practice. Rather, they are a temporal, dynamic and intermingling process. To appreciate the complexity of both, we need to look closely at the discursive resources, i.e., discourses of diversity; embodied resources, i.e., embodiment of diversity and embodied orientation towards others; and management technologies in diversity work.

Another major critique focuses on the assumptions of identity underlying diversity work. Diversity initiatives often take demographic attributes, such as gender, race and ethnicity, as strong predicators of group identities, and many are known for focusing on single categories of identities (Holck et al. 2016). This position is theoretically rooted in a social psychology that views individual identities as fixed, stable, coherent and unified (ibid.). The danger of such perspectives is that they may reduce diversity training to a set of techniques and information "about them" (D’Cruz 2007, p. 36). Such essentialist approaches to identity also dovetail structuralist theories that associate dominant groups with privilege and power, and marginalised groups with dispossession. This position is known to be divisive and has led to "backlash" against equity measures; particularly affirmative actions (ibid.). In contrast to essentialist views of identity, researchers from feminist, critical and poststructuralist schools have pinpointed that identities are socially constructed, multiple and intersectional (Dennissen et al. 2020), and that they can also be fragmented, emergent, performative and continuously in the making (D'Cruz 2007). While holding powerful potential, these critical constructs of identities have yet to be translated into solid empirical work (Holck et al. 2016).

Related to the issue of identity is the ontological nature of difference and diversity, which has direct implications for our imagination of sites of intervention or mobilisation. Maddy Janssens and Chris Steyaert (2019) suggest that the field of diversity work features an ontological dualism: individualism (persons) versus societism (structures). The former, evident in essentialist approaches to diversity, is the trend to ascribe differences to individual cognitive and behavioural characteristics. The latter, exemplified in the work of critical diversity scholars, perceives diversity as "historically determined structural asymmetries between social demographic 
groups" (ibid., p. 520). Therefore, to intervene in the structural power imbalances, researchers have directed their attention to the textual and discursive environment that constitutes diversity work and the subject positions of diversity workers. To break away from the ontological dualism, Janssens and Steyaert (2019) refer to the practice turn in social sciences (Schatzki 2001), and propose approaching diversity work as it is accomplished within a nexus of real-time practices which are simultaneously discursive, embodied and material.

\section{Diversity work as a process of lifelong learning}

Extending Janssens and Steyaert's (2019) work, we propose conceptualising diversity work as a process of lifelong learning for both individuals and organisations. Although rarely a preoccupation within the diversity literature, learning is presupposed in diversity initiatives. Kwon and Nicolaides (2017), for instance, note three modes of learning associated with diversity work: one-loop learning, which focuses on individuals' behaviour changes, double-loop learning, which involves change in people's cognitive schemas (Argyris and Schon 1974), and triple-loop learning, which is about bringing changes to our existential being. All three forms of learning, however, take individuals as the sites of intervention, placing faith in the possible alignment of individual intentions, actions and outcomes. By proposing diversity work as a process of lifelong learning, we do not downplay the importance of individual learning. Yet, we stress that learning is a distributed responsibility, which is simultaneously personal and organisational, and we direct attention to social practices that constitute learning (Shan 2015a, 2017).

Multiple efforts have been made to conceptualise learning as it is derived from social practices (e.g., Fenwick and Nerland 2014). For instance, Stephen Billet and Jennifer Newton's (2010) model of lifelong professional learning stresses learning as an effect produced through everyday professional practice. A learning practice comprises a duality of workplace affordances and the quality of an individual's participation in work and learning. Billet and Newton argue that "the potential of a learning practice will be best realised through the enactment of supportive practices ... and effortful engagement by learners" (ibid., p. 52). Based on research within the healthcare sector, they pinpoint a range of practices through which workplace pedagogies can be implemented for maximum effect. These are (1) guidance provided to workers by more experienced practitioners, i.e., mentoring; (2) workplace support that assists individuals with skills development; (3) a "workplace curriculum", i.e., the sequencing and pathways of work activities through which individuals progress in skills development; and (4) guided learning strategies (ibid., p. 56).

When considering the quality of individual participation in learning practices, Billett and Newton (2010) state that it is not enough to examine individual epistemological acts such as reflection. This may seem to be an unwarranted call since reflection, particularly critical reflection that addresses issues of power, is useful for individuals to become cognisant of practical consciousness (Giddens 1979) in their everyday conduct. What Billett and Newton are suggesting, though, is that reflection is never individualistic. Rather, they argue, it necessarily has a social and collective 
dimension (ibid.). This recognition prompted David Boud (2010) to refer to "the reflective turn" in professional practices (ibid., p. 29). Specifically, Boud argues for "productive reflection", which is organisational in intent, collective in orientation, contextualised within work, connecting learning and work, involving multiple stakeholders, generative rather than instrumental in focus, and, most importantly, open and shifting over time. Adeline Goh (2019) similarly recognises "both the individual and social dimensions of reflective practice", arguing that learning is in part about "becoming through participating" (ibid., p. 2) in social practices. Goh proceeds to propose two forms of collective reflective practice: groups reflecting on organisational intent, and individuals reflecting in the presence of others. The reflective turn (Boud 2010), rationalist in orientation, also sits on an ontology of relationality. The idea is that we, as embodied beings, depend on one another for a liveable life, and this existential dependency is precarious, since it relies on mutual recognition (Tyler 2019). While dominant recognition practices order, organise and normalise differences in binary terms (men versus women, heterosexual versus homosexual, white versus black, etc.) and in hierarchical manners, diversity work is necessarily implicated in mediating our relationality constituted through this "market of recognition" (Butler and Athanasiou 2013).

It is worth noting that the practice-based approach to learning, with its emphasis on collective reflection, is descriptive of what happens during the learning process. By proposing diversity work as a lifelong learning process, we also wish to acknowledge the varying ideological orientations that might be articulated through adult and lifelong learning today. These include, according to Richard Bagnall and Steven Hodge (2018), the disciplinary approach, which values what is true and real; the constructivist approach, which values authentic engagement in cultural settings; the emancipatory approach, which values knowledge that empowers, and the instrumentalist approach, which values knowledge as it lends people control of and in the world through rational reasoning. The instrumentalist approach seems to have prevailed despite being subject to considerable criticism. Yet, given the increasing demand for individual and collective flexibility in the context of diversity, Bagnall and Hodge (ibid.) suggest that instrumentalism might be giving way to situational or alternative epistemologies which are locally orchestrated.

\section{The context of our study and an introduction to S.U.C.C.E.S.S., our partner organisation}

Canada is a country of colonisation and immigration built on the land of Indigenous peoples. While the country has historically prioritised immigrants with white European backgrounds, since the 1960s, it has opened its doors to immigrants from other countries, which has added to the ethnic and cultural diversity of the nation. According to the most recent available Canadian census, ${ }^{2}$ in $2016,21.9 \%$ of Canadians were foreign-born (Statistics Canada 2017). Asia was the top source continent

\footnotetext{
${ }^{2}$ The data collected for the 2021 census have not yet been published.
} 
of recent immigrants, followed by Africa. In the same census, Canadians reported more than 250 ethnic origins, and four in ten people reported more than one origin (ibid., p. 1). Shifting diversity or super-diversity (Vertovec 2007), in terms of ethnic backgrounds, languages spoken, religious beliefs and so on, have become and will remain a defining feature of the working context for staff delivering immigrant services.

Immigrant services in Canada are typically delivered by non-profit, communitybased organisations, with funding provided mainly by the government, often on a fixed-term contract- and project-related basis (Shan 2015b; Richmond and Shield 2005). While immigrant services were historically conceptualised to assimilate immigrants to the host society, today they have adopted the ideal of two-way integration, i.e., mutual adaptation between newcomers and the host society. S.U.C.C.E.S.S. is one of many community-based organisations serving immigrants in Canada. Founded in 1973 by a passionate group of immigrant volunteers who identified and strove to bridge the gap of services for the Chinese communities, S.U.C.C.E.S.S. has played a critical role in adult education and community development since its inception (Guo 2006). Over time, it has grown into one of the largest non-profit, charitable, social service agencies that serves all immigrants to Canada. Today, S.U.C.C.E.S.S. offers a wide range of programmes and services in $45+$ languages to benefit $72,000+$ clients from $150+$ countries. The vision driving S.U.C.C.E.S.S. is that of a vibrant Canadian society where people thrive and contribute to inclusive communities. Its mission is to empower people on their Canadian journey to achieve their goals through services and advocacy that promote belonging, wellness and independence.

\section{Research questions and methodology}

As mentioned earlier, the purpose of our study was to inquire into diversity practices that are effective in fostering social equity and inclusion at work. We were particularly interested in how an organisation might expand its capacity to support staff in their engagement with immigrant newcomers across social differences. We selected S.U.C.C.E.S.S. as our partner because the organisation has had a history of promoting services for, and advocating on behalf of, racialised immigrants (Guo 2006). Our study, which we conducted over 16 months (September 2019 to December 2020) focused on two research questions:

(1) What does S.U.C.C.E.S.S. do as an organisation to orient its staff members towards diversity work and foster it among them? and

(2) How do staff members at S.U.C.C.E.S.S. learn and work with diversity issues?

This article focuses on research findings related mainly to the first question. 


\section{A partnership case study}

In terms of methodology, we chose the format of a partnership case study. A partnership approach positions community partners as collaborators and co-researchers rather than the subject (or object) of studies (Butterwick and Roy 2016). In doing so, it enables community-based knowledge to emerge in the course of the research and ensures that the knowledge produced is relevant and useful to the community. In its capacity as our research partner, S.U.C.C.E.S.S. was involved in the drafting of our initial research questions; in the research design, the data collection and the analysis; and in the dissemination of the research findings. In our study, we treated S.U.C.C.E.S.S. as the case, i.e., a bounded system for analysis (Merriam 1998; Stake 1995), while bearing in mind that this system is enmeshed within professional and institutional networks.

\section{Data collection and analysis}

Our field research involved multiple data collection methods. To understand organisational diversity management and training approaches, we conducted key informant interviews with one trainer, and four managers. These interviews, which lasted on average an hour each, and were conducted in English, focused on the development of diversity initiatives within the organisation, including diversity management policies and practices, and training programmes and pedagogies used to assist staff to engage with diversity among the staff, clients, community partners and other stakeholders.

S.U.C.C.E.S.S. also shared with the research team training materials and policies linked to the enactment of diversity work. Additionally, we also conducted nonparticipatory observations of an online diversity training session, and watched three other recorded diversity training sessions - due to the COVID-19 situation, all the training sessions were held online through Zoom. We analysed the policy and training documents and the training sessions to identify the organisation's pedagogical and policy orientations regarding diversity work.

To inquire into frontline workers' diversity work and learning experiences, we conducted four arts-informed ${ }^{3}$ focus group discussions ( 2 or 3 participants in each) and one-on-one interviews with frontline workers (12 in total) in English. The focus group discussions involved the participants either bringing an artefact or choosing one from the research team's collection that resonated the most with their experiences of working with issues of diversity and then speaking about their choices. The focus groups helped individuals to come together face-to-face to co-construct knowledge through interaction with the artefacts as well as among other group members.

\footnotetext{
${ }^{3}$ Arts-informed research "is a mode and form of qualitative research that is influenced by, but not based in, the arts. The methodology infuses the languages, processes, and forms of literary, visual, and performing arts into scholarly inquiry for purposes of advancing knowledge. The main purposes of artsinformed research are: to enhance understanding of the complexities of the human condition through alternative processes and representational forms of inquiry; and to reach multiple audiences by making scholarship more accessible" (MacCallum 2021).
} 
All interviews and focus group discussions were audio-recorded and transcribed verbatim. Transcripts were shared with participants for member checking. We used NVivo to code and analyse the data thematically in relation to the research questions, and each document was analysed by three university-based researchers. Our co-researcher from S.U.C.C.E.S.S. reviewed and verified our combined analysis to ensure its accuracy and relevance to the organisation.

In the next section, we report our findings with regard to the organisational practices constitutive of our partner organisation's frontline workers' diversity learning and work. All names used are pseudonyms.

\section{Research findings}

Originally a community organisation devoted to bridging gaps in services for Chinese-speaking immigrants, S.U.C.C.E.S.S. has redefined its mission and transformed into a culturally diverse organisation. In 2016, S.U.C.C.E.S.S. formed a Diversity and Inclusion (D\&I) Committee, composed of "diversity champions" from different divisions. The Committee develops, recommends and implements actions that build the organisation's diversity and inclusion capacities. This includes identifying and implementing training for staff and promoting inclusive service delivery. In 2020, in the face of a sharp rise in racism during COVID-19, an anti-racism working group was formed as part of the D\&I Committee. Previously, the organisation endorsed a policy of cultural appropriateness, aiming to provide services that are culturally and linguistically suitable in the delivery of their wide range of services. In 2019, this policy was replaced by a D\&I policy. The organisation's D\&I statement promotes "the safety, health and well-being of all members of our communities" (S.U.C.C.E.S.S. 2021), and recognises "shared histories of injustice and discrimination" (ibid.), against which it operates. It values the diverse identities, experiences and perspectives of all people including "their heritage, culture, language, age, gender identity and expression, LGBTQ2SI identity, ability, physical and mental health, religion, education, socio-economic background, family, and immigration status" (ibid.).

In practice, S.U.C.C.E.S.S. simultaneously endorses intercultural learning and intersectional and anti-racism approaches to diversity. The diversity initiatives that S.U.C.C.E.S.S. has implemented range from diversity hiring, promotion of equity, respect for diverse identities and expression, building relationships between newcomers and Indigenous people, fostering anti-oppressive communication, unpacking unconscious biases for both individual and organisation, trauma-informed and culturally relevant practices, as well as professional ethics and professional boundarymaking. It is clear that there is a will on the part of the organisation to work towards diversity and inclusion.

While it is unequivocal that S.U.C.C.E.S.S. is committed to issues of diversity and inclusion as an organisation, our study focused more on the workplace practices through which organisational commitments and intentions shape individuals' diversity work and learning. Specifically, our study points to a learning curriculum implemented by the organisation to engage in diversity and inclusion, which includes 
building a diverse organisation, supporting continuous learning at work, and providing diversity training which is directive but at the same time also generative.

\section{Building a diverse and inclusive organisation: people, place, space}

S.U.C.C.E.S.S. is intent on building a diverse organisation. This is reflected in its hiring practices, as well the efforts it has made to build its physical place and symbolic space to accommodate people of different social and cultural backgrounds. As S.U.C.C.E.S.S. transformed into a multicultural organisation, serving immigrants from all backgrounds, its workforce also diversified. In one of its policy documents, the organisation states that the recruitment of staff is based upon, among others, "the criterion of cultural competence. This may include language abilities, cultural understanding and/or community experience with the targeted client group according to the job requirement" (internal document). The need for a diverse workforce is driven by the demographic change associated with recurring waves of migration, governmental investment in issues of integration and the organisation's desire to provide culturally and linguistically appropriate services when it comes to immigrant settlement. One of the managers we interviewed shared the following example:

“[T]he government ... put aside X dollar[s] just to serve Syrian [refugees]. Everyone submits the proposals and we got fund[ed] ... Before 2014 and 2015, we only ha[d] one Arabic-speaking [member of] staff, and then, we grew up from one to [a] team of twenty." (Lilian)

A diverse workforce creates a work environment where staff from different backgrounds feel valued. Sam, for instance, shared that when working in an organisation where the majority of his colleagues are immigrants,

"It makes you feel ... safe ... it makes you feel like [everyone is working with] the best intentions for all the different communities in mind. ... It feels like a safe haven for different cultures ... different ethnic groups ... we had a lady from India. She wore a sari to work one day just because she wanted to ... she's allowed to do that to express her culture .... I can express ... both [of my] cultures in my workplace and ... it's OK." (Sam)

The culturally safe space described by Sam related above is not merely embodied by the diversity of the workforce, but it is also evident in the culturally sensitive material and symbolic space that the staff try to produce. A managerial staff member shared this insight with us:

"In order for cultural safety to be there ... there's a lot I can do to influence the possibility of an increased feeling of safety for you in this moment. It might be the way that I have certain posters on the wall, or the way that I welcome you, or the wording that I choose in a sign or brochure. All different pieces that can actually signal to you that you're safe without me saying [it] ... It is important ... to become aware of what might be something that I need to know about myself and my own bias about other people." (Renee) 
In this case, Renee's efforts to create a culturally safe space involved her working to identify and reflect on her own limitation and biases.

To give another example, when S.U.C.C.E.S.S. began hiring and serving an increasing number of Arabic-speaking people, most of whom would identify as Muslim, the organisation started modifying the cultural and physical space to accommodate the new arrivals.

"We have been [serving diverse clients] for many years now ... there were ... times for us to adjust to a big influx of Arabic-speaking [newcomers]. Everybody starts to learn about .... Ramadan ... since 2015 , we have more colleagues who observe Ramadan, ... clients, students who observe Ramadan. We have to be understand[ing] and flexible ... [People] cannot drink, ... cannot eat, and [people] have to pray ... So ... we adapt the staff schedules to make it flexible for them, while ... maintaining the current level of service. ... We turn some of the room into a praying room." (Lilian)

\section{Supporting continuous learning opportunities at work}

"[W]orking in this position ... you have to learn on the job because ... every client is different ... [E]ven though they may have [the] same problems, ... how they ... respond is different ... we always need support from other senior staff members ... Even though we may see clients one-to-one, ... we still work as a team, we have to share a lot of cases so that we learn as a team." (Winnie)

As Winnie suggests, there is rarely a uniform solution to the problems that newcomers face. As such, frontline workers need to engage in continuous learning to "expand" (Sean) their approaches and repertoire of knowledge and resources to be effective at work. In our study, we found that there are a multitude of informal learning spaces, some of which are built into the job design, and others are facilitated through informal association among peers. The effectiveness of all these learning spaces is contingent on the quality of reflection of individuals in the presence of others (Goh 2019).

In some divisions of the organisation, job shadowing has been used, which allows new employees to observe how experienced colleagues work through different cases. Sometimes, shadowing also involves workplace rotation. This type of shadowing is meant to provide staff members with a space to develop first-hand knowledge of the contexts as well as the challenges facing different client groups. Danielle shared:

“[T]here's always things like job shadowing, ... it can be a very different experience than if you work in a different region. So, for example, ... our front desk staff here ... in the Downtown Eastside ... deal with a lot of Chinese senior ... And then if you go to our Tri Cities office, it's very diverse. ... when I say the job shadowing, I mean, it's kind of like get out of your region and try something else ... being in [a] different environment." (Danielle)

In addition to job shadowing, guided learning from more experienced staff (Billet and Newton 2010) was also mentioned by our research participants as a significant 
resort. According to some, more experienced staff not only provide guidance around how to complete tasks, and how to navigate resources, but they sometimes also offer emotional support. Cecillia shared:

"I have a direct supervisor ... who I can come to and say, hey, ... this is what I'm experiencing. How can I do this? ... and I can tell her when I'm feeling frustrated or I'm raging ... So, that helps a lot and understanding what are the supports that are available to me. What are the systems that are in place to support that? I appreciate that and I appreciate that there is that support available. So even though, you know, I'm having those difficult conversations [with staff around differences in expectation], I do have the support behind me around how to handle [them]." (Cecillia)

In addition to opportunities built into job designs, informal associations among staff also facilitate meaningful learning. Sean shared his experience of welcoming newcomers into the team:

"[We] have many language capacities ... Within the very tiny [workspace], you will experience ... many different type of nationalities ... So we share our lives, basically very diverse lives and very diverse opinions on particular topics. We always debate and talk about world peace ... things we are witnessing, ... different types of people ... acting [in] different way[s].” (Sean)

Noting the importance for peers to learn from one another, some divisions at S.U.C.C.E.S.S. have built in some informal sharing time during team meetings. It is in these informal slots that individual members of staff sometimes vent frustrations, ask questions, learn from colleagues from different backgrounds, have their beliefs discussed and debated, and expand their horizon of knowledge and perspectives.

\section{Providing diversity training, both directive and generative}

“[T]he philosophy ... at S.U.C.C.E.S.S., ... we're talking 2016, is a culture of learning .... The main idea is that from top to bottom, it is good for everyone to be on the same page [in terms of training]." (Renee)

S.U.C.C.E.S.S. offers training of various kinds. Among others, it provides a set of standardised online training modules that settlement staff need to complete, including one on professional boundaries and ethics. These training modules might be considered instrumentalist and directive, since they are directly related to the operation of the settlement sector. However, there are good reasons for including them. S.U.C.C.E.S.S.'s professional ethics and boundaries are one of the competencies demanded of settlement workers by a multitude of actors. They include "respect for client confidentiality"; "maintenance of professional relationships (healthy boundaries)"; "prevention and avoidance of conflicts of interest"; and "understanding one's role and limitations" (Koltermann and Scott 2018, p. 39). Crucially, this training is coupled with an equity agenda. Danielle commented: 
"There's a whole module on professional boundaries and ethics, which is a really important component. ... it's hard ... because you're developing relationships with people. And yes, people are just trying to be nice and kind [with gifting], but it's an inherent power imbalance ... And that never ends, whether you're serving them as a client or even after when they're not a client." (Danielle)

Many S.U.C.C.E.S.S. workers share cultural backgrounds or immigration trajectories with clients, and human services are highly personal work. A few of our research participants mentioned issues such as emotional burnout when they struggled at the border of the personal and the professional. Professional ethics training offers reference points for staff members to deliberate on boundary issues.

S.U.C.C.E.S.S. also provides training programmes with the explicit goal of expanding staff members' knowledge and skills on issues of diversity and inclusion. Among other activities, it has invited experts to deliver training on topics including the Canadian Charter of Rights and Freedoms (GoC 1982), LGBTQ+ competency and inclusion, anti-oppression, unconscious bias, inclusive language, and indigeneity and reconciliation. While S.U.C.C.E.S.S. has historically offered in-person training in Metro (or Greater) Vancouver, it moved training online during the COVID-19 pandemic, which has actually allowed the training to reach more staff across service locations and time zones.

When examining all the training sessions, we found some features to be particularly conducive to diversity learning. First, the topics selected were timely, often in response to the difficult conversations arising among some members of the public. For instance, during the pandemic, racism became rampant. S.U.C.C.E.S.S. took initiative by inviting speakers to address issues of ethnocentrism. The organisation also held anti-racism response training sessions to provide participants with the skills to move from being silent bystanders when faced with racist incidents to becoming active witnesses. Second, the training sessions provided were relatable. Speakers frequently opened the sessions with cultural stories and personal experiences, often experiences of discrimination, indifference and injustice, with which workshop participants could easily identify. Third, the training sessions offered guidance in terms of practices, providing conceptual heuristics that help people name and navigate the multiplicity and intersectionality of identities, politics of language and culture, and issues of power and privileges. Finally, the training sessions aimed to be useful in practice. In this regard, they are not prescriptive, but generative of responses. This is achieved through activating real-life and work scenarios to enable collective reflection among the staff members participating in the training sessions.

One training session that a number of research participants referred to was a Movie Afternoon organised around a one-hour documentary entitled All Our Father's Relations (Yoshizawa 2016), which is about the journey of a family that has mixed Chinese and Musqueam (First Nations) heritage. Si shared the experiences of participating in the training event.

"So [after the] documentary ... we had ... quite a long discussion amongst a group of about ... twenty staff [member]s from different programmes [on] what the impression was ... and how we could actually bring that understanding to 
the everyday job that we're facing ... at the end of the thing, the management ... was actually collecting opinions of what kind of topics that we would like to see [for] the next meetup." ( $\mathrm{Si}$ )

Training sessions like this are set up with clear organisational intent. By mobilising this documentary as a cultural resource, the D\&I Committee aimed to provoke discussion and enhance consciousness around issues such as the head tax, the Indian Act, residential schools, and trauma. ${ }^{4}$ Frontline staff appreciated that the discussion connected learning with work (see Boud 2010). Individuals participated in the discussion and reflection from different locations given their respective social and cultural biographies and trajectories. Some of them were inspired by the stories, some identified with the experiences shared, and others were exposed to issues of indigeneity for the first time.

It is worth noting that for topics outside of S.U.C.C.E.S.S.'s scope of expertise, the organisation has made use of training opportunities provided by community partners. Furthermore, S.U.C.C.E.S.S. has also organised community dialogues, round tables and workshops to foster greater awareness and understanding of issues of diversity and inclusion at the community level. Sometimes, we heard, S.U.C.C.E.S.S. plays a direct role in disrupting existing discourses of diversity in the sector. For instance, Cecillia shared the following:

"[The community partners] actually wanted a training on what's important for each culture. And I was like, but doesn't that create stereotypes? ... what about if we do something around intercultural competency? ... I don't want to be the one that starts off ... these stereotypes. Like ... these particular populations want this and don't like that. But that's not true because each person is different. ... And I'm like, well, I understand you want that type of training, but that's also not the training that I want to provide. But we can work on something similar, actually more interesting and more appropriate. And so that's where the intercultural competency training came about, because we wanted to provide a training, so to speak, ... without creating stereotypes." (Cecillia)

By intercultural learning, Cecillia meant the introduction of an intersectional approach $^{5}$ to understanding identities, having "authentic conversations" with

\footnotetext{
${ }^{4}$ Briefly, head tax is a tax that Chinese immigrants had to pay to enter Canada. It was levied under the Chinese Immigration Act passed in 1885, when Canada stopped needing Chinese workers after the completion of the Canadian Pacific Railway. The tax was abolished in 1923, and was replaced with the Chinese Exclusion Act, in force until 1947, which banned Chinese from immigrating to Canada.

The original Indian Act (GoC 1876) aimed to eliminate First Nations culture. The Act has been amended several times to remove discriminatory sections. Today the 1985 version of the Act (GoC 2019 [1985]) is still in force.

So-called residential schools were established by the Canadian government and run mostly by the Roman Catholic church (a few were run by Protestants) for more than a century (1883-1996). Several generations of children from Indigenous families were forcefully removed from their homes and put in these boarding schools to forget their culture and their language. Many of them did not survive - their unmarked graves were discovered on the sites of several of the schools in August 2021.

5 An intersectional approach, initially proposed by Kimberlé Crenshaw (1991), acknowledges the interconnectedness of identities in terms of ethnicity, gender etc.
} 
partners and participants, asking "difficult questions", questioning the meaning of culture, and building "deeper" connections beyond food and music.

\section{Discussion and conclusion}

Equity activism has effected positive changes in the legal and policy realm. As a result, diversity and inclusion have become an organisational priority in major post-industrial countries such as Canada. Existing literature on diversity work has generated much knowledge on the barriers in diversity management and training. In this article, we turned our attention to tried-and-tested organisational practices that are conducive to diversity work and learning; practices created and adopted by S.U.C.C.E.S.S., a multicultural immigrant services organisation in Canada. Conceptually, this article positions diversity work as a process of lifelong learning that is simultaneously individual and organisational. Our particular focus is on the workplace practices that facilitate the space of diversity learning (Billet and Newton 2010). Within that focus, we address the spaces produced at work that are generative of productive and collective reflection, and continuous reflection in the presence of others (Boud 2010; Goh 2019).

Our study found three major areas of practices that constitute a learning curriculum for diversity work at S.U.C.C.E.S.S. These are (1) building a diverse organisation; (2) supporting continuous learning at work, (3) and providing diversity training. S.U.C.C.E.S.S. works to build a diverse organisation by engaging in diverse hiring practices, and by moving the organisation deliberatively (with informed intent) towards a culturally safe place. With regard to continuous learning, we found that spaces of learning are built into the organisation of work, both formally and informally. Through job shadowing, senior colleagues' support (mentoring) and informal association among employees, staff members encounter others and other narratives in a supported space. In terms of diversity training, we picked up two pulses running through the same vein of the organisation. One aims to standardise staff members' understanding of issues of professional ethics. The other aims to induct staff into the discursive consciousness promoted in an activist public. While it might be easy to associate the former with an instrumentalist need of the organisation for order, and the latter with equity activism, the distinction between the two might not be that clear-cut. The former offers an ethical reference for staff to navigate settlement work as a highly relational and emotional complex. The latter exposes staff to proactive discourses, and to heuristic tools which they may use to name, query and respond to what is taken for granted, and what might be immobilising in daily work and life.

Diversity work is not without its challenges at S.U.C.C.E.S.S. There are issues of funding, issues of staff turnover - given the project-based hiring practices within the immigrant services sector - and issues of time for and accessibility of in-house training. To some extent, the last issues were overcome during the pandemic as training was moved to online platforms. The findings of our study, however, have significant theoretical and empirical implications for diversity work within organisations. In particular, our study provides both theoretical heuristic and empirical reference points for researchers/practitioners to approach diversity work as a process of 
lifelong learning. Specifically, it pinpoints a range of workplace practices that can be considered as sites of practical intervention and units of analysis for diversity learning. These practices, i.e., building a diverse organisation, supporting continuous learning and providing diversity training, essentially involve the assembly of individuals with varying personal histories and experiences, physical places, symbolic spaces, cultural narratives, discursive consciousness, and organisational intentions and orientations.

It must be said that some of the workplace practices discussed are more directive than others. Together, though, they are generative of responses and engagements. In other words, they are more inductive than prescriptive, providing opportunities for staff members to continuously reflect, in the presence of others if not collectively (Boud 2010; Goh 2019), on issues of culture and difference, so that they may navigate cultural narratives and practices deliberatively and with care at work. It is in those reflective cultural encounters that people start opening their practical consciousness to be witnessed, corroborated, as well as interrupted by others. It is also through these reflective moments that S.U.C.C.E.S.S. builds its organisational capacity to respond to the shifting context of diversity. Finally, our study points to the idea that considering diversity work using the binary constructions of instrumentalism and equity activism may not be helpful. We suggest that it might be more important to understand how the various ideological orientations get articulated in specific situations (Bagnall and Hodge 2018), irrespective of whether they work in conjunction or in competition with one another.

Acknowledgement We acknowledge the funding support of a Social Science and Humanities Research Counsel (SSHRC) Engage Grant (15R01345), without which this study would not have been possible.

\section{References}

Ahmed, S., \& Swan, E. (2006). Doing diversity. Policy Futures in Education, 4(2), 96-100. https://doi. org/10.2304/pfie.2006.4.2.96

Argyris, C., \& Schon, D. A. (1974). Theory in practice: Increasing professional effectiveness. Jossey-Bass.

Bagnall, R., \& Hodge, S. (2018). Contemporary adult and lifelong education and learning: An epistemological analysis. In M. Milana, S. Webb, H. Holford, R. Waller, \& P. Jarvis (Eds.), The Palgrave international handbook on adult and lifelong education and learning (pp. 13-34). Palgrave Macmillan.

Ballard, D., Allen, B., Ashcraft, K., Ganesh, S., McLeod, P., \& Zoller, H. (2020). When words do not matter: Identifying actions to effect diversity, equity, and inclusion in the academy. Management Communication Quarterly, 34(4), 590-616. https://doi.org/10.1177/0893318920951643

Billett, S., \& Newton, J. (2010). A learning practice: conceptualising professional lifelong learning for the health-care sector. In H. Bradbury, N. Frost, S. Kilminster, \& M. Zukas (Eds.), Beyond reflective practice: New approaches to professional lifelong learning (pp. 52-65). Routledge.

Boud, D. (2010). Relocating reflection in the context of practice. In H. Bradbury, N. Frost, S. Kilminster, \& M. Zukas (Eds.), Beyond reflective practice: New approaches to professional lifelong learning (pp. 25-36). Routledge.

Butterwick, S., \& Roy, C. (Eds.). (2016). Working the margins of community-based adult learning. Sense Publishers.

Butler, J., \& Athanasiou, A. (2013). Dispossession: The performative in the political. Polity Press. 
Crenshaw, K. (1991). Mapping the margins: Intersectionality, identity, and violence against women of color. Stanford Law Review, 43(6), 1241-1299. https://doi.org/10.2307/1229039

D'Cruz, H. (2007). Working with "diverse bodies, diverse identities": An approach to professional education about "diversity." International Journal of Inclusive Education, 11(1), 35-57. https://doi.org/10.1080/ 13603110500375457

Dennissen, M., Benschop, Y., \& van den Brink, M. (2020). Rethinking diversity management: An intersectional analysis of diversity networks. Organization Studies, 41(2), 219-240. https://doi.org/10.1177/ 0170840618800103

Ely, R. J., \& Meyerson, D. E. (2000). Advancing gender equity in organizations: The challenge and importance of maintaining a gender narrative. Organization, 7(4), 689-708. https://doi.org/10.1177/13505 0840074005

Fenwick, T., \& Nerland, M. (2014). Reconceptualising professional learning: Sociomaterial knowledges, practices and responsibilities. Routledge.

Fraser, N. (1997). Justice interruptus: Critical reflections on the "postsocialist" condition. Routledge.

Giddens, A. (1979). Central problems in social theory. University of California Press.

GoC (Government of Canada) (1876). An Act to amend and consolidate the laws respecting Indians (Indian Act). Parliament of the Dominion of Canada. Retrieved 13 October 2021 from https://www.canadiana. ca/view/oocihm.9_08051_5_1/213?r=0\&s=1

GoC. (1982). Canadian charter of rights and freedoms. Part I of the Constitution Act, 1982. Ottawa, ON: Ministry of Justice, Government of Canada. Retrieved 11 October 2021 from https://laws-lois.justice. gc.ca/eng/Const//page-12.html\#h-40

GoC. (2019 [1985]). Indian Act (R.S.C., 1985, c. I-5), last amended 15 August 2019. Ministry of Justice, Government of Canada. Retrieved 13 October 2021 from https://laws-lois.justice.gc.ca/eng/acts/i-5/

Goh, A. Y. S. (2019). Rethinking reflective practice in professional lifelong learning using learning metaphors. Studies in Continuing Education, 41(1), 1-16. https://doi.org/10.1080/0158037X.2018.1474867

Guo, S. (2006). Adult education for social change: The role of a grassroots organisation in Canada. Convergence, 39(4), 107-122.

Hiranandani, V. (2012). Diversity management in the Canadian workplace: Towards an antiracism approach. Urban Studies Research. https://doi.org/10.1155/2012/385806

Holck, L., Muhr, S. L., \& Villeseche, F. (2016). Identity, diversity and diversity management: On theoretical connections, assumptions and implications for practice. Equality, Diversity and Inclusion, 35(1), 48-64. https://doi.org/10.1108/EDI-08-2014-0061

Janssens, M., \& Steyaert, C. (2019). A practice-based theory of diversity: Respecifying (in)equality in organizations. Academy of Management Review, 44(3), 518-537. https://doi.org/10.5465/amr.2017.0062

Kahn, A. (2013). Diversity work in organizations: A narrative study of external diversity practitioners. Journal of Psychological Issues in Organizational Culture, 3(S1), 174-189. https://doi.org/10.1002/jpoc. 21099

Klarsfeld, A., Ng, E., \& Tatli, A. (2012). Social regulation and diversity management: A comparative study of France, Canada and the UK. European Journal of Industrial Relations, 18(4), 309-327. https://doi. org/10.1177/0959680112461091

Koltermann, I., \& Scott, D. (2018). The competencies of frontline settlement practitioners in Canada: A background research report. eCaliber Group/Calience Research and Consulting. Retrieved 8 October 2021 from https://km4s.ca/wp-content/uploads/The-Competencies-of-Frontline-Settlement-Workers-inCanada-A-Background-Research-Report-December-17-2018-FINAL.pdf

Kwon, C. K., \& Nicolaides, A. (2017). Managing diversity through triple-loop learning: A call for paradigm shift. Human Resource Development Review, 16(1), 85-99. https://doi.org/10.1177/1534484317690053

MacCallum, L. (2021). Arts-informed research guide [online resource]. Mount Saint Vincent University Library. Retrieved 12 October 2021 from https://libguides.msvu.ca/arts-informed-research.

Merriam, S. B. (1998). Qualitative research and case study applications in education. Jossey-Bass.

Mirchandani, K., \& Butler, A. (2006). Beyond inclusion and equity: Contributions from transnational antiracist feminism. In A. M. Konrad, P. Prasad, \& J. K. Pringle (Eds.), Handbook of workplace diversity (pp. 475-488). SAGE.

Nkomo, S. M., Bell, M. P., Roberts, L. M., Joshi, A., \& Thatcher, S. M. (2019). Diversity at a critical juncture: New theories for a complex phenomenon. Academy of Management Review, 44(3), 498-517. https://doi.org/10.5465/amr.2019.0103

O’Leary, J., \& Sandberg, J. (2017). Managers' practice of managing diversity revealed: A practice-theoretical account. Journal of Organizational Behavior, 38(4), 512-536. https://doi.org/10.1002/job.2132

OED online (Oxford English Dictionary online) (2021). Diversity. Oxford University Press. Retrieved 8 October 2021 from https://www.oed.com/view/Entry/56064?redirectedFrom=diversity 
Richmond, T., \& Shields, J. (2005). NGO-government relations and immigrant services: Contradictions and challenges. Journal of International Migration and Integration/revue De L'integration et de la Migration Internationale, 6(3-4), 513-526. https://doi.org/10.1007/s12134-005-1024-3

Schatzki, T.R. (2001). Introduction: Practice theory. In T. Schatzki, K. Knorr Cetina \& E. von Savigny (Eds), The practice turn in contemporary theory (pp. 1-14), Routledge.

Shan, H. (2015a). Distributed pedagogy of difference: Reimagining immigrant training and education. Canadian Journal for Studies in Adult Education, 27(3), 1-16.

Shan, H. (2015b). Towards a participatory model of governance: Settlement services in the training and education of immigrants. New Directions for Adult and Continuing Education, 146, 19-28. https://doi.org/ 10.1002/ace.20128

Shan, H. (2017). Reconfiguring the learning space: Skilled immigrants in Canada. In M. Milana, S. Webb, H. Holford, R. Waller, \& P. Jarvis (Eds.), The Palgrave international handbook on adult and lifelong education and learning (pp. 687-706). Palgrave McMillan.

Stake, R. E. (1995). The art of case study research. SAGE Publications.

Statistics Canada. (2017). Immigration and ethnocultural diversity: Key results from the 2016 Census. The Daily, 25 October. Statistics Canada. Retrieved 31 December 2020 from https://www150.statcan.gc.ca/ n1/daily-quotidien/171025/dq171025b-eng.pdf

S.U.C.C.E.S.S. (United Chinese Community Enrichment Services Society) (2021). Commitment to diversity $\&$ inclusion [dedicated webpage]. S.U.C.C.E.S.S. Retrieved 11 October 2021 from https://successbc.ca/ learn-about-us/our-commitment-to-diversity-inclusion/.

Swan, E., \& Fox, S. (2010). Playing the game: Strategies of resistance and co-optation in diversity work. Gender, Work, and Organization, 17(5), 567-589. https://doi.org/10.1111/j.1468-0432.2010.00524.x

Tyler, M. (2019). Reassembling difference? Rethinking inclusion through/as embodied ethics. Human Relations, 72(1), 48-68. https://doi.org/10.1177/0018726718764264

Vertovec, S. (2007). Super-diversity and its implications. Ethnic and Racial Studies, 30(6), 1024-1054. https://doi.org/10.1080/01419870701599465

Yoshizawa, A. (2016). All our father's relations [documentary film]. University of British Columbia Theatre \& Film, and other partners. Synopsis, official trailer, etc. available at https://allourfathersrelations.com/

Young, I. M. (2011). The scaling of bodies and the politics of identity. In I. M. Young (Ed.), Justice and the politics of difference (pp. 122-155). Princeton University Press.

Zanoni, P., Janssens, M., Benschop, Y., \& Nkomo, S. (2010). Guest editorial Unpacking diversity, grasping inequality: Rethinking difference through critical perspectives. Organization, 17(1), 9-29. https://doi. org/10.1177/1350508409350344

Publisher's Note Springer Nature remains neutral with regard to jurisdictional claims in published maps and institutional affiliations.

Hongxia Shan PhD, is an Associate Professor in the Department of Educational Studies at the University of British Columbia. She specialises in migration and adult education, lifelong learning, work and learning, pedagogies of difference, and qualitative research.

Amy Cheng is the Director of Strategic Initiatives and Integration at the United Chinese Community Enrichment Services Society (S.U.C.C.E.S.S.) in Vancouver. She is passionate about promoting diversity and inclusion within organisations.

Nasim Peikazadi is a PhD candidate in the Department of Educational Studies at the University of British Columbia. Her doctoral research focuses on a critical understanding of identity negotiations of Iranian migrants within transnational social and emotional sites.

Yeonjoo Kim is a PhD student in the Department of Educational Studies at the University of British Columbia. Her research focuses on the changing relationships of learning, work, and life of South Korean "millennials". 


\section{Authors and Affiliations}

\section{Hongxia Shan ${ }^{1}$ (D) Amy Cheng ${ }^{2} \cdot$ Nasim Peikazadi $^{1} \cdot$ Yeonjoo Kim $^{1}$}

Amy Cheng

info@success.bc.ca

Nasim Peikazadi

nasim.peikazadi@ubc.ca

Yeonjoo Kim

yeonjook@mail.ubc.ca

1 Department of Educational Studies, University of British Columbia, Vancouver, BC, Canada

2 S.U.C.C.E.S.S., Vancouver, BC, Canada 